\title{
Detection of cancer cells disseminated in bone marrow using real-time quantitative RT-PCR of CEA, CK19, and CK20 mRNA in patients with gastric cancer
}

\author{
Yasuki Fujita, Masanori Terashima, Yutaka Hoshino, Satoshi Ohtani, Seigo Kashimura, Norio Kanzaki, \\ Fuminiko Osuka, Michiniko Kogure, and Mitsukazu Gotoh \\ Department of Surgery 1, Fukushima Medical University, 1 Hikarigaoka, Fukushima 960-1295, Japan
}

\begin{abstract}
Background. To determine the significance of bone marrow disseminated tumor cells in gastric cancer, we investigated the mRNA expression levels of carcinoembryonic antigen (CEA), cytokeratin 19 (CK19), and cytokeratin 20 (CK20) using the real-time quantitative reverse-transcription polymerase chain reaction (RQ-PCR).

Methods. Bone marrow samples were aspirated from the sternum at the time of surgery in 65 patients with resectable gastric cancer. Total RNA was extracted from bone marrow; and the expression levels of CEA, CK19, and CK20 mRNA were determined by RQ-PCR using an ABI PRISM 7000 and quantified against the GAPDH mRNA level.

Results. The detection limits of these genes were determined in the gastric cancer cell line MKN-45 and the colon cancer cell line $\mathrm{C}-1$, which had been serially diluted in peripheral blood mononuclear cells (PBMCs). A rate of 1 cancer cell/ million PBMCs was obtained by detecting CEA and CK19 mRNA in MKN-45 and by detecting CK20 mRNA in C-1. In the clinical samples, only 1 of the 65 gastric cancer patients (1.5\%) who had stage IV disease was positive for CEA, CK19, and CK20 mRNA; none of CEA, CK19, or CK20 mRNA was positive in the remaining 64 patients. No significant correlation was observed between disseminated cancer cells in bone marrow and clinicopathological features, including simultaneous or metachronous hepatic metastasis and patient Survival.

Conclusion. The incidence of disseminated cancer cells in bone marrow in our study appears low, unlike that in previous reports. The significance of disseminated cancer cells in bone marrow may also be quite low in gastric cancer.
\end{abstract}

Key words Bone marrow - Disseminated cancer cells . Cytokeratin $19 \cdot$ Cytokeratin $20 \cdot$ Carcinoembryonic antigen

Offprint requests to: $\mathrm{M}$. Terashima

Received: April 21, 2006 / Accepted: August 15, 2006

\section{Introduction}

In advanced gastric cancer, the incidence of recurrence at a distant site is as high as $50 \%$, despite prior extended lymph node dissection. The most common relapse site is the peritoneum. The detection of disseminated cancer cells in the peritoneal cavity is of great advantage when predicting peritoneal recurrence and patient prognosis [1]. We previously reported that the level of carcinoembryonic antigen (CEA) mRNA expression, adjusted against the GAPDH mRNA level in the peritoneal cavity, is a good predictor of peritoneal recurrence and is an independent prognostic factor in patients with gastric cancer [2].

The second most frequent cause of treatment failure in gastric cancer is hematological recurrence, such as liver metastasis. To predict hematological recurrence, detection of disseminated cancer cells in bone marrow has been extensively investigated in breast [3-6], colorectal $[7,8]$, and non-small-cell lung $[9,10]$ cancer. In breast cancer, the consensus is that the presence of disseminated cancer cells in the bone marrow is associated with a poor prognosis [6]. However, in gastric cancer, unlike breast cancer, the number of reports is limited, and no consensus has been reached regarding the correlation between the presence of disseminated tumor cells in bone marrow and patient survival. Significant correlation with disease-free or overall survival has been reported in studies using immunohistochemistry with anti-cytokeratin antibody [11-13]. However, Heiss et al. [14] reported that immunocytochemistry using cytokeratin (CK)-18 alone did not demonstrate a significant difference in survival, but that the addition of urokinase-type plasminogen activator receptor double staining did produce a significant difference in overall and disease-free survival. In addition, Schott et al. [15] reported that their peritoneal cavity results correlated with the 4-year survival rate, but positive results in the bone marrow showed little significance. Furthermore, 
no standardized procedure for detecting disseminated cancer cells in bone marrow has been established. Immunocytochemistry using monoclonal antibodies against $\mathrm{CK}$ is the most popular procedure; however, a recent molecular biological protocol using the realtime quantitative reverse transcription polymerase chain reaction (RQ-PCR) targeting CEA or CK appears to be an attractive method with high objectivity and quantifiability. Unlike immunocytochemistry, there had been few reports describing the usefulness of CK-18; on the contrary, CK-19 has been most extensively studied in breast cancer [5], and promising results had been reported with CK-20 in gastric cancer [16,17] as a marker for the PCR technique. Therefore, among the several kinds of CKs, CK-19 and CK-20 are thought to be good candidates for detecting disseminated cancer cells in bone marrow using RQ-PCR. Thus, to evaluate the clinical significance of detecting bone marrow-disseminated cancer cells in patients with gastric cancer, we investigated the CEA, CK-19, and CK-20 mRNA expression levels in bone marrow using RQ-PCR.

\section{Materials and methods}

\section{Cell lines}

The human gastric cancer cell line MKN-45, obtained from the Riken Cell Bank (Institute of Physical and Chemical Research, Saitama, Japan), and the human colon cancer cell line C-1, obtained from IBL Fujioka (Gunma, Japan) were incubated in RPMI-1640 medium containing 10\% fetal calf serum (Invitrogen, Carlsbad, $\mathrm{CA}, \mathrm{USA}$ ) at $37^{\circ} \mathrm{C}$ in $5 \% \mathrm{CO}_{2}$.

\section{Patients}

A total of 65 patients (48 men, 17 women; age range 1882 years, mean 64 years) who underwent gastrectomy and had histologically proven gastric carcinoma between November 2000 and April 2003 were enrolled in the study. Written informed consent was obtained from all patients. Tumor characteristics were determined according to the Japanese Classification of Gastric Carcinoma [18] and are listed in Table 1. The depth of tumor invasion ( $\mathrm{T}$ category) and extent of lymph node metastasis ( $\mathrm{N}$ category) were determined by the histological diagnosis.

Macroscopic peritoneal metastasis was observed in three patients, and all of these patients were had positive cytology. Synchronous liver metastasis was confirmed in four patients. Of the 65 patients, 37 had a T1 tumor, 17 had a T2 tumor, 10 had a T3 tumor, and 1 had a T4 tumor. Lymph nodes were involved
Table 1. Patients' clinical characteristics

\begin{tabular}{|c|c|}
\hline Clinicopathological factor ${ }^{\mathrm{a}}$ & No. of patients \\
\hline \multicolumn{2}{|l|}{ Sex } \\
\hline Male & 48 \\
\hline Female & 17 \\
\hline \multicolumn{2}{|l|}{ Peritoneal metastasis } \\
\hline Absent & 62 \\
\hline Present & 3 \\
\hline \multicolumn{2}{|l|}{ Hepatic metastasis } \\
\hline Absent & 61 \\
\hline Present & 4 \\
\hline \multicolumn{2}{|l|}{ Cytology in peritoneal washings } \\
\hline Negative & 62 \\
\hline Positive & 3 \\
\hline \multicolumn{2}{|l|}{ Depth of tumor invasion } \\
\hline $\mathrm{T} 1$ & 37 \\
\hline $\mathrm{T} 2$ & 17 \\
\hline T3 & 10 \\
\hline $\mathrm{T} 4$ & 1 \\
\hline \multicolumn{2}{|l|}{ Extent of lymph node metastasis } \\
\hline 0 & 47 \\
\hline N1 & 9 \\
\hline N2 & 6 \\
\hline $\mathrm{N} 3$ & 3 \\
\hline \multicolumn{2}{|l|}{ Stage } \\
\hline IA & 33 \\
\hline IB & 17 \\
\hline II & 2 \\
\hline IIIA & 2 \\
\hline IIIB & 2 \\
\hline IV & 9 \\
\hline \multicolumn{2}{|l|}{ Histological type } \\
\hline Papillary adenocarcinoma & 3 \\
\hline $\begin{array}{l}\text { Well differentiated tubular } \\
\text { adenocarcinoma }\end{array}$ & 20 \\
\hline $\begin{array}{l}\text { Moderately differentiated tubular } \\
\text { adenocarcinoma }\end{array}$ & 15 \\
\hline $\begin{array}{l}\text { Poorly differentiated } \\
\text { adenocarcinoma (solid type) }\end{array}$ & 4 \\
\hline $\begin{array}{l}\text { Poorly differentiated } \\
\text { adenocarcinoma (diffuse type) }\end{array}$ & 13 \\
\hline Signet-ring cell carcinoma & 7 \\
\hline Mucinous adenocarcinoma & 3 \\
\hline
\end{tabular}

${ }^{a}$ Clinicopathological factors were determined according to the Japanese Classification of Gastric Carcinoma

in 18 patients ( $\mathrm{N} 1$ in 9 patients, $\mathrm{N} 2$ in 6 patients, N3 in 3 patients). Consequently, tumor stage was determined as IA in 33 patients, IB in 17 patients, II in 2 patients, IIIA in 2 patients, IIIB in 2 patients, and IV in 9 patients.

In one patient at stage IV, curative resection was enabled owing to extended peritoneal resection. Therefore, curative surgery involving gastrectomy and adequate lymphadenectomy (D0 in 4, D1 in 32, D2 in 23 , and D3 in 6) was performed in 57 patients, and noncurative surgery involving simple gastrectomy without extended lymphadenectomy was performed in 8 patients. 


\section{Cell spiking}

A cell spiking study was performed to determine the sensitivity of this RQ-PCR technique for detecting cancer cells in peripheral blood mononuclear cells (PBMCs). Peripheral venous blood was obtained from healthy volunteers, and PBMCs were separated out by differential centrifugation. Gastric cancer MKN-45 cells and colon cancer C-1 cells were serially diluted to $1 \times 10^{6}$ cells to one cell in the PBMCs, and the total number of cells then adjusted to $1 \times 10^{7}$ cells. Total RNA was extracted from each cell fraction; and RQ-PCR for CEA, CK19, and CK20 mRNA was then performed as described below. The preliminary experiments indicated that the CK20 expression level was quite low in MKN45 cells, and thus C- 1 cells were used for the CK20 spiking analysis. In the present study, the threshold of detection of mRNA resulted in a detection rate of 1 cancer cell per $1 \times 10^{7}$ PBMCs.

\section{RNA extraction and $c D N A$ synthesis}

A 20-ml aliquot of bone marrow was aspirated from the sternum under general anesthesia at the time of surgery. Samples were centrifuged at $1500 \mathrm{~g}$ for $5 \mathrm{~min}$ before washing with cold phosphate-buffered saline (PBS). Cells were then suspended in Isogen reagent (NipponGene, Tokyo, Japan) and stored at $-80^{\circ} \mathrm{C}$.

Frozen cells in Isogene were thawed, and total RNA was extracted using the acid-guanidiniumisothiocyanate-phenol-chloroform method. Ethachinmate (Nippon Gene) was added to the samples as the RNA carrier. Before performing reverse transcription, total RNA was incubated with DNase I (Invitrogen) to remove contaminating genomic DNA. Total RNA $(1 \mu \mathrm{g})$ was reverse-transcribed using a random hexamer (Applied Biosystems, Foster City, CA, USA) and SuperScript II reverse transcriptase (Invitrogen). The reaction mixture was incubated for 1 hat $37^{\circ} \mathrm{C}$, then at $90^{\circ} \mathrm{C}$ for $10 \mathrm{~min}$, and stored at $-20^{\circ} \mathrm{C}$. The integrity of the isolated RNA was established by RT-PCR analysis of the housekeeping gene, glyceraldehyde-3phosphate dehydrogenase (GAPDH), as described elsewhere [1].

\section{Real-time quantitative polymerase chain reaction}

CEA-, CK19-, and CK20-specific oligonucleotide primers and a fluorogenic probe were designed using Primer Express Software (Applied Biosystems). For CEA, the sense primer was $5^{\prime}$-CAT GAT TGG AGT GCT GGT TG-3', and the anti-sense primer was $5^{\prime}$-ACC AAG CCC AGC TCA TTT T-3'. The fluorogenic probe was 5'-(FAM) TTG CTC TGA TAT AGC AGC CCT GGT G (TAMRA)-3'. For CK19, the sense primer was 5'ACC ATT GAG AAC TCC AGG ATT GTC-3', and the anti-sense primer was $5^{\prime}$-CTC ATG CGC AGA GCC TGT T-3'. The fluorogenic probe was 5'(FAM)CAG ATG ACT TCC GAA CCA AGT TTG AGA CG (TAMRA)-3'. For CK20, the sense primer was $5^{\prime}$-GAA CGC CCG AAC AAC GAA TA-3', and the anti-sense primer was $5^{\prime}$-CAC GAC CTT GCC ATC CAC TA-3'. The fluorogenic probe was 5'(FAM)TGA ACA GGA AAT TGC TAC TTA CCG CCG C (TAMRA)-3'.

The RQ-PCR assay was performed using the ABI PRISM 7000 Sequence Detection System (Applied Biosystems). The PCR reaction proceeded in a mixture $(50 \mu \mathrm{l})$ containing $200 \mathrm{nM}$ of each primer, $5 \mu \mathrm{M}$ of probe, $25 \mu \mathrm{l}$ of TaqMan Universal PCR Master Mix (Applied Biosystems), and $5 \mu \mathrm{l}$ of cDNA template. Fifty cycles of amplification were performed at $95^{\circ} \mathrm{C}(15 \mathrm{~s})$ and $60^{\circ} \mathrm{C}$ (1 min); and CEA, CK19, and CK20 mRNA expression levels were normalized against quantified GAPDH mRNA expression.

\section{Statistical analysis}

Statistical analysis was performed using a personal computer and StatView V.5.0 software (SAS Institute, Cary, NC, USA). The chi-squared test was used to evaluate the correlation between positive results and clinicopathological factors. Survival curves were calculated using the Kaplan-Meyer method and compared with the log-rank test. $P<0.05$ was considered statistically significant. To evaluate the correlation between two variables, linear regression analysis using logarithmic data was performed, and Pearson's correlation coefficient was calculated (see Fig. 2, below).

\section{Results}

Sensitivity of $R Q-P C R$ and determination of threshold levels

Amplification plots for CEA and CK19 and CK20 in the cell spiking study using MKN45 and C-1 cells are shown in Fig. 1. Specific amplification of each gene was observed at as low as one cancer cell in $1 \times 10^{7}$ PBMCs. No amplification of CEA (Fig. 1A) or CK20 (Fig. 1C) was observed in the PBMCs alone; however, low-level amplification of CK19 was detected in PBMCs after 40 cycles, suggesting the presence of nonspecific amplification (Fig. 1B).

The expressii Álevel of each gene normalized against GAPDH demonstrated linear correlation with the number of cells ranging from $1 \times 10^{6}$ cells to one cell for each gene (Fig. 2). We defined the mRNA expression level of 1 cell in $1 \times 10^{7}$ PBMCs as the threshold for further analysis. 
A

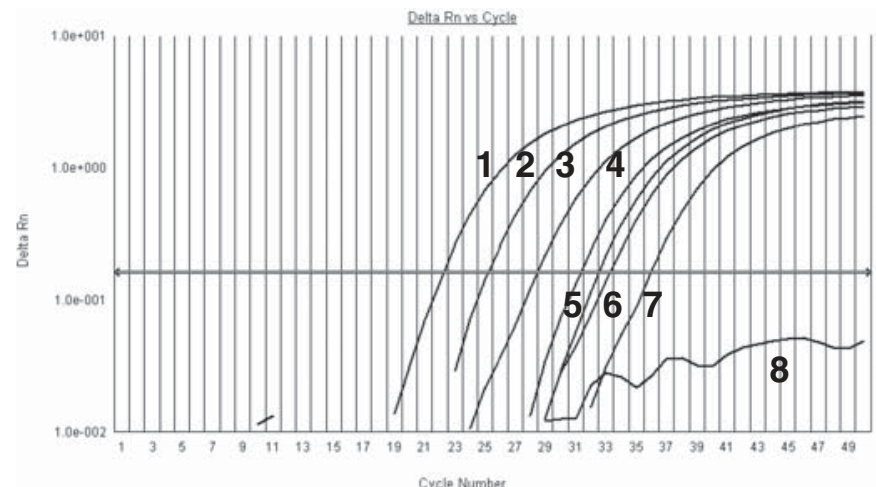

C

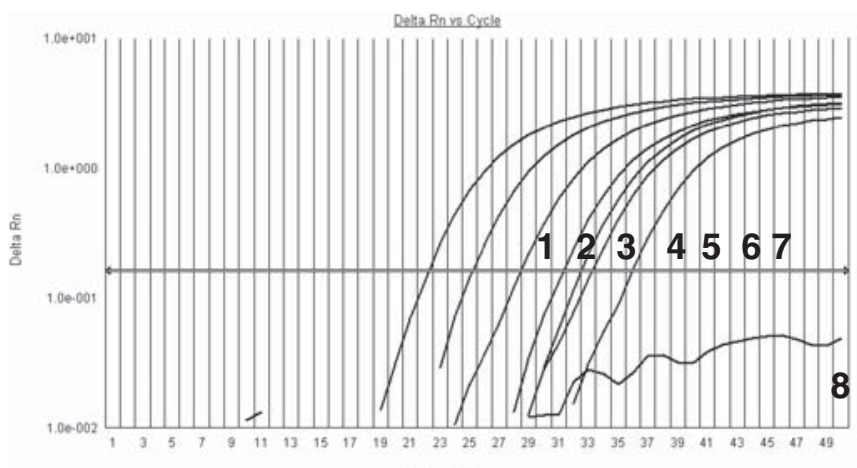

Cycle Number
B

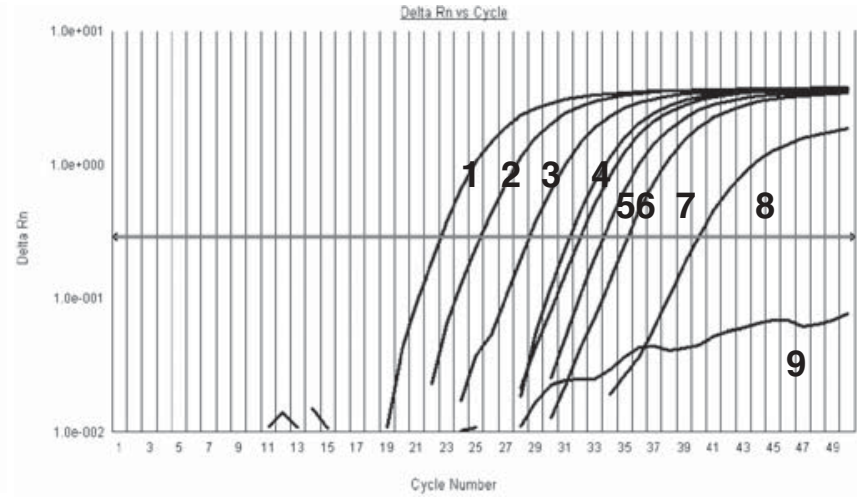

Cycle Number

Fig. 1. Amplification plots of carcinoembryonic antigen (CEA) (A), CK19 (B), and CK20 (C) mRNA following serial 10 -fold dilutions from $1 \times 10^{6}$ to one cancer cell, represented by plots 1-7 [MKN45 in (A) and (B) and $C 1$ in $(\mathbf{C})]$ in peripheral blood mononuclear cells (PBMCs). The total number of cells was adjusted to $1 \times 10^{7}$ for all reactions. CEA, CK19, and CK20 mRNA was detectable at the level of one cancer cell. Expression of CEA and CK20 in PBMCs alone (plot 8) was not detectable, although low levels of CK19 mRNA were detected in PBMCs alone. Plot 9 represents no template control
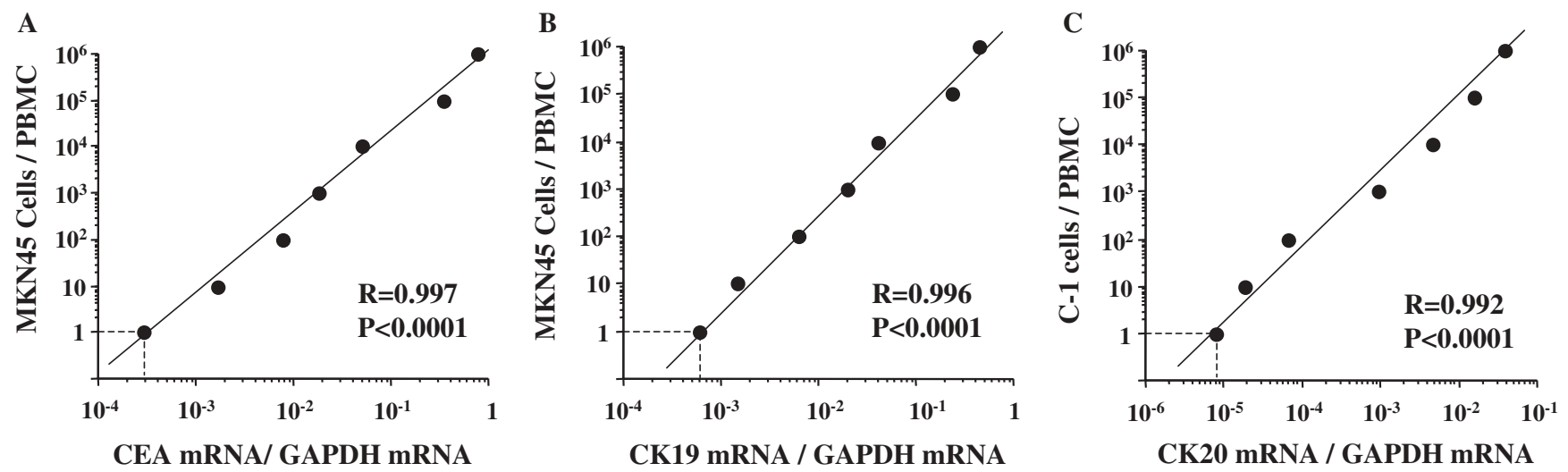

Fig. 2. Linear correlation between CEA (A), CK19 (B), and CK20 (C) mRNA levels normalized against GAPDH mRNA and the number of MKN45 $(\mathbf{A}, \mathbf{B})$ or C-1 $(\mathbf{C})$ cells from $1 \times 10^{6}$ to one cell

\section{Evaluation of expression of CEA, CK19, and CK20 mRNA in bone marrow}

Samples from all 65 patients were evaluated for CEA, CK19, and CK20 mRNA using the RQ-PCR assay. Measurable amounts of CEA mRNA were detected in the samples from 4 of the 65 patients at the level ranging from $1.86 \times 10^{-6}$ to $3.28 \times 10^{-4}$ (mean $8.59 \times 10^{-5}$ ). The CEA mRNA expression level in one patient was above the threshold and was judged positive. CEA mRNA expression was not detected in the remaining 61 samples. In these 61 samples, and in 3 samples with a CEA mRNA level below the threshold, CEA mRNA was defined as negative. Therefore, the positivity rate of CEA mRNA was 1 in 65 (1.5\%) (Fig. 3A).

CK19 mRNA was detected in samples from 59 of the 65 patients at levels ranging from $8.57 \times 10^{-4}$ to $1.46 \times$ $10^{-1}$ (mean $1.3 \times 10^{-2}$ ); none was detected in the remainder. In 1 of the 59 patients with detectable CK19 mRNA expression, the CK19 mRNA level was above the 
A

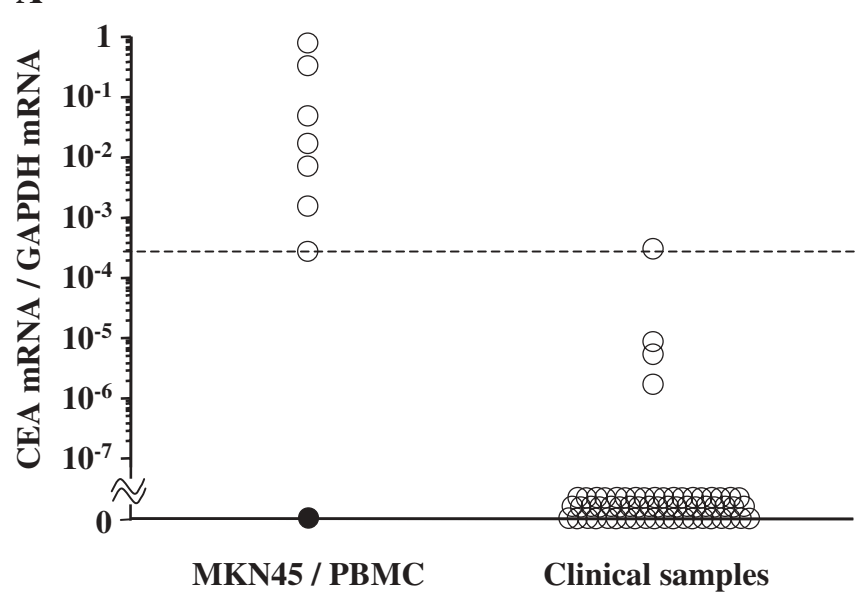

C

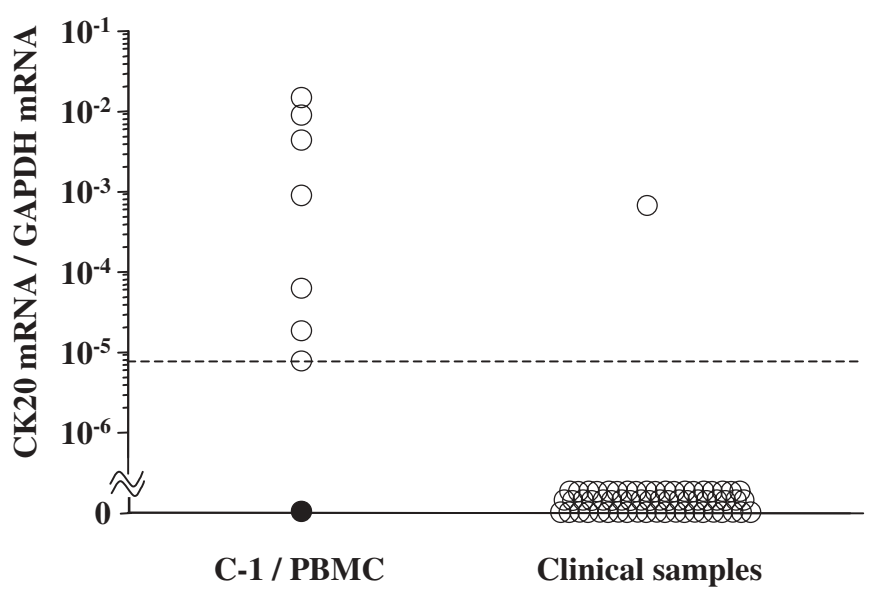

threshold and was judged positive. In 6 samples without positive amplification and in 58 with a CK19 mRNA level below the threshold, CK19 mRNA was classified as negative. The positive rate for CK19 was also 1 in 65 $(1.5 \%)$ (Fig. 3B).

Measurable amounts of CK20 mRNA were detected from only one sample of the 65 patients, at the level of $7.15 \times 10^{-4}$. The CK20 mRNA expression level in this patient was above the threshold and was judged positive. Therefore, the positivity rate of CK20 mRNA was 1 in 65 (1.5\%) (Fig. 3C).

Using the CEA, CK19, and CK20 RQ-PCR assays, only 1 of the 65 patients $(1.5 \%)$ was determined to be positive. The clinical features of this patient were $\mathrm{T} 4$, $\mathrm{N} 3$, and P1 (having peritoneal metastasis), and the tumor was classified as stage IV according to the Japanese Classification of Gastric Carcinoma with the histological type of poorly differentiated adenocarcinoma. He underwent palliative gastrectomy to relieve his symptoms and died of cancer 6 months after surgery. Of the 64 patients with negative mRNA expression in the bone
B

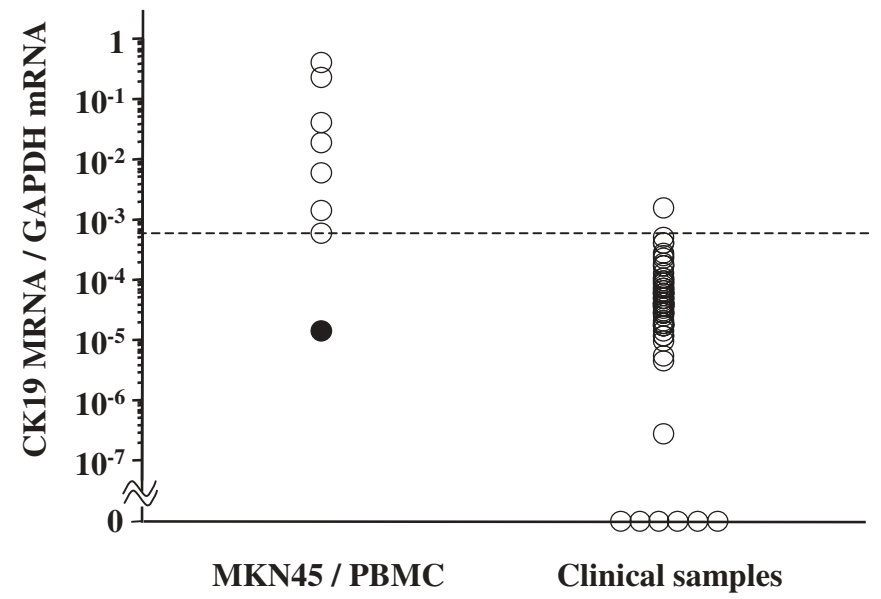

Fig. 3. Expression levels of CEA (A), CK19 (B), and CK20 (C) mRNA normalized against GAPDH mRNA in bone marrow samples. The broken line represents the threshold as determined by the cell spiking analysis. Open circles, cancer cells or bone marrow samples; closed circle, PBMCs. CEA mRNA were detected in the samples from 4 of the 65 patients (A). CK19 mRNA was detected in samples from 59 of the 65 patients (B). CK20 mRNA was detected from only 1 sample of the 65 patients $(\mathbf{C})$. Of the 65 clinical samples, only 1 was determined to be positive for CEA, CK19, and CK20

marrow, 6 patients experienced recurrence (4 with hepatic metastasis, 2 with peritoneal metastasis) and died of cancer. No significant correlations were observed between CEA, CK19, or CK20 mRNA expression levels and clinicopathologic factors, including survival.

\section{Discussion}

In the present study, we quantitatively measured the expression levels of CEA, CK19, and CK20 using RQ-PCR to evaluate the clinical significance of bone marrow-disseminated cancer cells in patients with gastric cancer. The results were in stark contrast with previous findings of high bone marrow dissemination in patients with gastric cancer. We were able to detect bone marrow-disseminated cancer cells in only 1 of 65 patients with a variety of gastric cancer stages using a threshold level determined by cell spiking analysis.

The detection of disseminated cancer cells in bone marrow was first described in gastric cancer by 
Schlimok et al. [11] using immunocytochemistry with an anti-CK18 antibody. They reported that tumor cells in bone marrow were detected in 34 of 97 patients (35\%). Thereafter, several investigators also demonstrated the presence of disseminated tumor cells in bone marrow using the same method and reported positivity rates of $33 \%-53 \%[12,19,20]$. Soeth et al. [16] reported that CK20 mRNA-positive samples were detected in 11 of $49(22 \%)$ gastric cancer patients using nested RT-PCR. Using RQ-PCR, Oki et al. [17] reported that CK20 mRNA was detected in 27 of 45 patients $(60 \%)$. Compared with these results, the present data exhibit an extremely low positivity rate in bone marrowdisseminated cells.

One possible explanation may be the high incidence of early gastric cancer in our series, which included more than half of the early gastric cancer patients. The incidence of hematological recurrence is less than $10 \%$ in early gastric cancer, which might accordingly result in a low incidence of positive disseminated cells in bone marrow. However, this explanation is not entirely robust, as Maehara et al. [21] reported that cytokeratinpositive cells were detectable in 9 of 45 patients (20\%), even with early gastric cancer.

The other possibility is the sensitivity of our assay method. With immunocytochemistry, one cancer cell per $1 \times 10^{5}$ to $1 \times 10^{6}$ bone marrow-derived cells is usually detectable $[3,22]$. In contrast, one cancer cell per $1 \times 10^{6}$ to $5 \times 10^{7}$ bone marrow-derived cells or PBMCs is usually detectable by nested RT-PCR [23] or RQPCR $[2,17]$ using cell spiking analysis with positive expression cell lines as the target genes. In the present study, we were able to detect one cancer cell per $1 \times 10^{7}$ PBMCs using the CEA, CK-19, and CK-20 genes. Therefore, the probability that the sensitivity of our system is lower than that of other studies using PCR technology or immunocytochemistry is slim.

The only probable explanation for our low positivity rate is the setting of the threshold level. For RQ-PCR, determining the threshold level is a problematic issue. In our previous study investigating CEA mRNA in peritoneal washings in patients with gastric cancer, we set the threshold at the mean plus two standard deviations of CEA mRNA levels in peritoneal washings from 20 patients with asymptomatic cholecystolithiasis $(1.01 \times$ $10^{-3}$ ) [2]. In the present study, we used a threshold in which one cancer cell per $1 \times 10^{7}$ PBMCs was detectable, which was much lower than that of our previous study. Yet, the positivity rate of CEA in the bone marrow samples was markedly lower than that in the peritoneal washings. CEA mRNA expression was detectable below the threshold level in three patients. However, even if treated as positive cases, there was still no correlation between CEA positivity and clinicopathological features or patient survival (data not shown).
In CK19, nonspecific amplification was observed after 40 cycles in the PBMCs-alone sample. Furthermore, the CK19 positivity rate changed according to the threshold level. For instance, when the threshold was set at $1 \times 10^{-4}$, the positivity rate was $35 \%$. However, we were unable to find any threshold levels that showed clinical significance when the threshold was arbitrarily changed. One possible explanation may be found in the study by Ruud et al. [24], in which they identified a novel pseudogene that shows a high degree of identity with the CK19 gene sequence. They also noted that the published primer sequences and reaction conditions used by several other groups to detect CK19 mRNA may have led to the amplification of this pseudogene. In line with this, previous work by others as well as the samples in the present study using CK19 as a marker need to be reassessed in the future.

The expression levels of CK20 were extremely low, except in one patient with very advanced disease. Oki et al. [17] investigated disseminated cancer cells in bone marrow using RQ-PCR in patients with gastric cancer and reported a CK20 positivity rate of $57 \%$. This difference in positivity compared with the present results may be due to the different PCR conditions used, in particular the primer and probe sequences. However, the procedure by Oki et al. to determine the threshold level was not documented. Jung et al. [25] investigated the diagnostic specificity of CK20 mRNA detection and found that CK20-expressing cells were positively identified as belonging to the granulocyte fraction of leukocytes. They concluded that positive CK20 expression in normal granulocytes must be considered in tests designed to detect disseminated cancer cells.

\section{Conclusion}

Based on the present results, we conclude that the clinical significance of detecting disseminated cancer cells in bone marrow, in particular using RQ-PCR, is quite low in patients with gastric cancer. To utilize this technology in the clinical setting, optimal conditions, including target genes and a standardized detection method, must be established, and there should be a comparison with an immunocytochemical method.

Acknowledgments The authors are grateful to M. Kato and K. Takayasu for their technical assistance.

\section{References}

1. Kodera $Y$, Nakanishi H, Ito S, Yamamura Y, Kanemitsu Y, Shimizu Y, et al. Quantitative detection of disseminated free cancer cells in peritoneal washes with real-time reverse transcriptase-polymerase chain reaction: a sensitive predictor of 
outcome for patients with gastric carcinoma. Ann Surg 2002;235: 499-506.

2. Oyama K, Terashima M, Takagane A, Maesawa C. Prognostic significance of peritoneal minimal residual disease in gastric cancer detected by reverse transcription-polymerase chain reaction. Br J Surg 2004;91:435-43.

3. Funke I, Schraut W. Meta-analyses of studies on bone marrow micrometastases: an independent prognostic impact remains to be substantiated. J Clin Oncol 1998;16:557-66.

4. Braun S, Cevatli BS, Assemi C, Janni W, Kentenich CR, Schindlbeck C, et al. Comparative analysis of micrometastasis to the bone marrow and lymph nodes of node-negative breast cancer patients receiving no adjuvant therapy. J Clin Oncol 2001;19: 1468-75.

5. Ozbas S, Dafydd H, Purushotham AD. Bone marrow micrometastasis in breast cancer. Br J Surg 2003;90:290-301.

6. Braun S, Vogl FD, Naume B, Janni W, Osborne MP, Coombes $\mathrm{RC}$, et al. A pooled analysis of bone marrow micrometastasis in breast cancer. N Engl J Med 2005;353:793-802.

7. Lindemann F, Schlimok G, Dirschedl P, Witte J, Riethmuller G. Prognostic significance of micrometastatic tumour cells in bone marrow of colorectal cancer patients. Lancet 1992;340:685-9.

8. Tsavellas G, Patel H, Allen-Mersh TG. Detection and clinical significance of occult tumour cells in colorectal cancer. Br J Surg 2001;88:1307-20

9. Pantel K, Izbicki J, Passlick B, Angstwurm M, Haussinger K, Thetter $\mathrm{O}$, et al. Frequency and prognostic significance of isolated tumour cells in bone marrow of patients with non-small-cell lung cancer without overt metastases. Lancet 1996;347:649-53.

10. Osaki T, Oyama T, Gu CD, Yamashita T, So T, Takenoyama M, et al. Prognostic impact of micrometastatic tumor cells in the lymph nodes and bone marrow of patients with completely resected stage I non-small-cell lung cancer. J Clin Oncol 2002;20: 2930-6.

11. Schlimok G, Funke I, Pantel K, Strobel F, Lindemann F, Witte J, et al. Micrometastatic tumour cells in bone marrow of patients with gastric cancer: methodological aspects of detection and prognostic significance. Eur J Cancer 1991;27:1461-5.

12. Maehara Y, Yamamoto M, Oda S, Baba H, Kusumoto T, Ohno S, et al. Cytokeratin-positive cells in bone marrow for identifying distant micrometastasis of gastric cancer. Br J Cancer 1996;73:837.

13. Jauch KW, Heiss MM, Gruetzner U, Funke I, Pantel K, Babic R, et al. Prognostic significance of bone marrow micrometastases in patients with gastric cancer. J Clin Oncol 1996;14:1810-7.
14. Heiss MM, Simon EH, Beyer BC, Gruetzner KU, Tarabichi A, Babic R, et al. Minimal residual disease in gastric cancer: evidence of an independent prognostic relevance of urokinase receptor expression by disseminated tumor cells in the bone marrow. J Clin Oncol 2002;20:2005-16.

15. Schott A, Vogel I, Krueger U, Kalthoff H, Schreiber HW, Schmiegel W, et al. Isolated tumor cells are frequently detectable in the peritoneal cavity of gastric and colorectal cancer patients and serve as a new prognostic marker. Ann Surg 1998;227:3729 .

16. Soeth E, Vogel I, Roder C, Juhl H, Marxsen J, Kruger U, et al. Comparative analysis of bone marrow and venous blood isolates from gastrointestinal cancer patients for the detection of disseminated tumor cells using reverse transcription PCR. Cancer Res 1997;57:3106-10.

17. Oki E, Maehara Y, Tokunaga E, Shibahara K, Hasuda S, Kakeji $\mathrm{Y}$, et al. Detection of disseminated cancer cells in bone marrow of gastric cancer using real time quantitative reverse transcriptase polymerase chain reaction. Cancer Lett 2002;188:191-8.

18. Japanese Gastric Cancer A. Japanese Classification of Gastric Carcinoma - 2nd English Edition. Gastric Cancer 1998;1:10-24.

19. Macadam R, Sarela A, Wilson J, MacLennan K, Guillou P. Bone marrow micrometastases predict early post-operative recurrence following surgical resection of oesophageal and gastric carcinoma. Eur J Surg Oncol 2003;29:450-4.

20. Funke I, Fries S, Rolle M, Heiss MM, Untch M, Bohmert H, et al. Comparative analyses of bone marrow micrometastases in breast and gastric cancer. Int J Cancer 1996;65:755-61.

21. Maehara Y, Hasuda S, Abe T, Oki E, Kakeji Y, Ohno S, et al. Tumor angiogenesis and micrometastasis in bone marrow of patients with early gastric cancer. Clin Cancer Res 1998;4:2129-34.

22. Seeliger H, Spatz H, Jauch KW. Minimal residual disease in gastric cancer. Recent Results Cancer Res 2003;162:79-87.

23. Gerhard M, Juhl H, Kalthoff H, Schreiber HW, Wagener C, Neumaier M. Specific detection of carcinoembryonic antigenexpressing tumor cells in bone marrow aspirates by polymerase chain reaction. J Clin Oncol 1994;12:725-9.

24. Ruud P, Fodstad O, Hovig E. Identification of a novel cytokeratin 19 pseudogene that may interfere with reverse transcriptasepolymerase chain reaction assays used to detect micrometastatic tumor cells. Int J Cancer 1999;80:119-25.

25. Jung R, Petersen K, Kruger W, Wolf M, Wagener C, Zander A, et al. Detection of micrometastasis by cytokeratin 20 RT-PCR is limited due to stable background transcription in granulocytes. $\mathrm{Br}$ J Cancer 1999;81:870-3. 